\title{
Article \\ Performance Study of Zn-Co-Ni/AC Catalyst in Acetylene Acetylation
}

\author{
Zhuang Xu ${ }^{1}{ }^{\oplus}$, Peijie He ${ }^{1}$, Yuhao Chen ${ }^{1}$, Mingyuan Zhu ${ }^{2}$, Xugen Wang ${ }^{1,2, *}$ and Bin Dai ${ }^{1,2, *}$ \\ 1 School of Chemistry and Chemical Engineering, Shihezi University, Shihezi 832000, China; \\ zhuangxu818@163.com (Z.X.); PeijieHe18@163.com (P.H.); chenyuhao@stu.shzu.edu.cn (Y.C.) \\ 2 Key Laboratory for Green Processing of Chemical Engineering of Xinjiang Bingtuan, Shihezi University, \\ Shihezi 832000, China; zhuminyuan@shzu.edu.cn \\ * Correspondence: wxgen@shzu.edu.cn (X.W.); db_tea@shzu.edu.cn (B.D.)
}

Citation: Xu, Z.; He, P.; Chen, Y.; Zhu, M.; Wang, X.; Dai, B. Performance Study of $\mathrm{Zn}-\mathrm{Co}-\mathrm{Ni} / \mathrm{AC}$ Catalyst in Acetylene Acetylation. Catalysts 2021, 11, 1271. https:// doi.org/10.3390/catal11111271

Academic Editor: Filippo Perna

Received: 9 October 2021

Accepted: 19 October 2021

Published: 22 October 2021

Publisher's Note: MDPI stays neutral with regard to jurisdictional claims in published maps and institutional affiliations.

Copyright: (c) 2021 by the authors. Licensee MDPI, Basel, Switzerland. This article is an open access article distributed under the terms and conditions of the Creative Commons Attribution (CC BY) license (https:// creativecommons.org/licenses/by/ $4.0 /)$.

\begin{abstract}
Zinc acetate $\left(\mathrm{Zn}(\mathrm{OAc})_{2}\right)$ loaded on activated carbon $(\mathrm{AC})$ is the most commonly used catalyst for the industrial synthesis of vinyl acetate (VAc) using the acetylene method. The aim of this study is to optimize the $\mathrm{Zn}(\mathrm{OAc})_{2} / \mathrm{AC}$ catalyst by adding co-catalysts to improve its activity and stability. Ternary catalysts were synthesized by adding $\mathrm{Co}$ and $\mathrm{Ni}$ to the $\mathrm{Zn}(\mathrm{OAc})_{2} / \mathrm{AC}$ catalyst $(\mathrm{Zn}-$ $\mathrm{Co}-\mathrm{Ni} / \mathrm{AC})$. Due to the strong synergistic effect among promoter $\mathrm{Co}, \mathrm{Ni}$, and the active component of $\mathrm{Zn}(\mathrm{OAc})_{2}$, the resulting catalyst is capable to absorb more acetic acid and less acetylene. The stability and activity of $\mathrm{Zn}-\mathrm{Co}-\mathrm{Ni} / \mathrm{AC}$ catalyst have been improved through electron transfer to alter the electron cloud density around the $\mathrm{Zn}$ element. Under the same reaction conditions, the activity of $\mathrm{Zn}-\mathrm{Co}-\mathrm{Ni} / \mathrm{AC}$ catalyst was enhanced by $83 \%$ compared to that of $\mathrm{Zn}(\mathrm{OAc})_{2} / \mathrm{AC}$, and the activity was still as high as $30.1 \%$ after $120 \mathrm{~h}$ of testing.
\end{abstract}

Keywords: ternary catalyst; acetylene acetylation; $\mathrm{Zn}-\mathrm{Co}-\mathrm{Ni} / \mathrm{AC}$

\section{Introduction}

As one of the biggest organic chemistry intermediates in the world, VAc has been used to produce a lot of downstream productions that are widely used in medicine, textile, machinery, construction, leather processing, and other fields [1-4]. At present, there are two main industrial production methods for VAc, one is the acetylene method represented in the equation below, using acetylene with acetic acid (HAc) as raw materials.

$$
\mathrm{C}_{2} \mathrm{H}_{2}+\mathrm{CH}_{3} \mathrm{COOH} \stackrel{\mathrm{Zn} / \mathrm{AC}}{\rightarrow} \mathrm{CH}_{2} \mathrm{CHCOOCH}_{3}
$$

The other using ethylene, acetic acid, and oxygen as raw materials is the ethylene method [5] below.

$$
\mathrm{C}_{2} \mathrm{H}_{4}+\mathrm{CH}_{3} \mathrm{COOH}+0.5 \mathrm{O}_{2} \stackrel{\mathrm{Pd} / \mathrm{Au}}{\rightarrow} \mathrm{CH}_{2} \mathrm{CHCOOCH}_{3}+\mathrm{H}_{2} \mathrm{O}
$$

The bimetallic Pd-Au catalyst system is used by the ethylene method and has good performance in industrial production, but the $\mathrm{Pd}$ and $\mathrm{Au}$ are expensive and their prices are on an upward trend [6,7]. The acetylene method is a simple technology, $\mathrm{Zn}(\mathrm{OAc})_{2} / \mathrm{AC}$ catalyst is low cost and has good catalytic performance. However, the $\mathrm{Zn}(\mathrm{OAc})_{2}$ / AC catalyst has the disadvantages of increasing the yield of by-products with rising temperature, besides, it has a short lifetime and can be deactivated easily.

Regarding active components, $\mathrm{Xu}$ et al. [8] loaded ionic liquid containing the active ingredient $\mathrm{Zn}(\mathrm{OAc})_{2}$ into porous silica gel to form a supported ionic liquid catalyst which exhibited good selectivity. Miyazawa et al. $[9,10]$ synthesized several highly active metal oxide catalysts, but there are obvious defects in terms of stability. In carrier modification, Bong and coworkers [11,12] modified the activated carbon with hydrogen peroxide, nitric 
acid and acetic acid, the adsorption capacity and the adsorption rate of zinc acetate with the catalyst were increased. Yan et al. [13] prepared the porous carbon sphere (PCS) and used it for supporting zinc acetate in a single pass operation performed at $220^{\circ} \mathrm{C}$, the conversions of acetic acid reached $22.6 \%$. In terms of engineering simulations and theoretical calculations, many researchers have done a lot of work on the reaction mechanism, active site, carrier modification and side reactions of VAc synthesis [14-19].

In the synthesis process of VAc by acetylene method, our group also have done some work on active components selection and carrier modification. A type of catalyst containing nitrogen with high activity was prepared by Yu et al. [20]. Wang and coworkers [21,22] used zinc-cobalt and zinc-nickel as active components and explained the relevant reaction mechanisms. Wang et al. [23] prepared nitrogen-doped AC by modifying AC with dicyandiamide (N-AC) and used it for loading $\mathrm{Zn}(\mathrm{OAc})_{2}$, which exhibited good performance. Zhu et al. [24] modified the catalyst with the supports of boron by simple impregnation method.

Skala and co-workers [25] explored zinc-nickel-cobalt as a catalyst for water oxidation reactions for the first time and which showed excellent activity. Zhu et al. [26] prepared a new type of electrode material GO/Zn-Co-Ni that layered double hydroxides with a fluffy cotton-like structure, showing a combination of carbon materials and ternary metals. For the acetylene-acetic acid based synthesis of VAc, the activity of different metal active components increase in the order: $\mathrm{Hg}(\mathrm{II})>\mathrm{Bi}>\mathrm{Cd}>\mathrm{Zn}>\mathrm{Ni}>\mathrm{Mg}>\mathrm{Co}>\mathrm{Fe}>\mathrm{Ca}>\mathrm{Ba}$ [9]. We noticed that $\mathrm{Zn}, \mathrm{Co}$, and $\mathrm{Ni}$ are active and able to interact with each other. Based on this, we synthesized Zn-Co-Ni/AC catalyst, which shows good activity and stability.

\section{Catalysts Characterization}

$\mathrm{N}_{2}$ adsorption-desorption isotherms were determined and obtained on an ASAP 2460 apparatus (Micromeritics, Norcross, Georgia, USA). BET surface areas, total pore volumes and average pore sizes were acquired based on the Brunauer-Emmett-Teller (BET) method together with the Barrett-Joyner-Halenda (BJH) method. TPD- $\mathrm{N}_{2}$ was performed by heating the sample from $25^{\circ} \mathrm{C}$ to $800{ }^{\circ} \mathrm{C}$ with a ramp rate of $10{ }^{\circ} \mathrm{C} / \mathrm{min}$ in $\mathrm{N}_{2}$ atmosphere. XPS data were measured using Kratos AXIS Ultra DLD X-ray photoelectron spectrometer from the Trafford Park, Manchester, UK. High-resolution TEM (HRTEM) data were performed by using a Tecnai G2 F20 instrument(FEI Company, Hillsboro, Oregon, USA). TG analysis was carried out on a NETZSCH STA 449F3 (Selp, Bavaria, Germany) Jupiter1 instrument and the test temperature was increased from $30^{\circ} \mathrm{C}$ to $850{ }^{\circ} \mathrm{C}$ at a rate

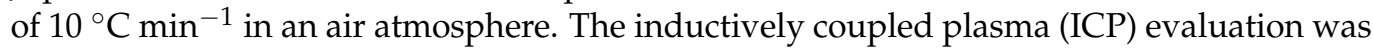
performed using the Agilent ICPOES 730 (Agilent Technologies, Santa Clara, CA, USA) for metal elemental measurement.

\section{Catalyst Evaluation}

As shown in Figure S1, Catalyst was evaluated in a fixed bed microreactor (i.d. of $10 \mathrm{~mm}$ ). We first filled a small amount of quartz wool into the bottom of the reaction tube and then added $5 \mathrm{~mL}$ of catalyst. The entire tube was purged with nitrogen before the reaction, and then the temperature of the preheater and reactor were controlled using a CKW-1100 temperature regulator (Beijing Chaoyang Automation Instrument Factory).

When the temperature of the preheater and reactor were adjusted to $150{ }^{\circ} \mathrm{C}$ and $180^{\circ} \mathrm{C}$, respectively, the peristaltic pump controlling the flow of acetic acid was turned on and the acetic acid was vaporized into the reactor after passing through the preheater to activate the catalyst in a 30-min process. The temperature of the reactor was adjusted to $220^{\circ} \mathrm{C}$, the nitrogen was turned off and acetylene was introduced into the reaction, where the flow of acetylene and nitrogen was controlled by a mass flow meter. After the product vinyl acetate was condensed by the condenser, the product was sampled per hour by a sample tube and was injected into the GC-9A gas chromatograph by the micro-injector for analysis. The acetylene space velocity was $500 \mathrm{~h}^{-1}$, the molar ratio of acetylene to acetic acid was $3: 1$, and the reaction temperature was $220^{\circ} \mathrm{C}$. 
The conversion of acetic acid, VAc selectivity and yield from acetic acid were defined according to the following equations:

$$
\begin{gathered}
\text { Conversion }=\frac{n_{0}-n_{1}}{n_{0}} \times 100 \% \\
\text { Selectivity }=\frac{n_{p}}{n_{0}-n_{1}} \times 100 \% \\
\text { Yield }=\frac{n_{p}}{n_{0}} \times 100 \%
\end{gathered}
$$

where in, $n_{0}$ represents the amount of acetic acid for feedstock before reaction; $n_{1}$ denotes amount of acetic acid for residue after reaction; and $n_{p}$ is amount of acetic acid for forming VAc. The calculation of carbon conservation is as shown in Table S1. The turnover frequency (TOF) and turnover number (TON) are as shown in Figure S4.

\section{Results and Discussions}

\subsection{Catalytic Performance Evaluation}

As can be seen from Table 1, at a theoretical loading of $10 \%$ for three monometallic catalysts. The $\mathrm{Co} / \mathrm{AC}$ and Ni/AC catalysts were basically inactive, and the Zn/AC catalyst had the best activity with acetic acid conversion of $19.9 \%$. Therefore, at this loading, the zinc acetate is the active phase.

Table 1. Effect of different active components on the performance of catalysts.

\begin{tabular}{ccc}
\hline Samples & Composition of Samples & Acetic Acid Conversion (\%) \\
\hline $\mathrm{Zn} / \mathrm{AC}$ & $10 \mathrm{wt} \% \mathrm{Zn}(\mathrm{OAc})_{2}$ & 19.9 \\
$\mathrm{Co} / \mathrm{AC}$ & $10 \mathrm{wt} \% \mathrm{Co}(\mathrm{OAc})_{2}$ & 4.8 \\
$\mathrm{Ni} / \mathrm{AC}$ & $10 \mathrm{wt} \% \mathrm{Ni}(\mathrm{OAc})_{2}$ & 4.4 \\
\hline
\end{tabular}

It can be seen from Figure 1a that different molar ratios of $\mathrm{Zn}, \mathrm{Co}$, Ni have significant influence on the catalyst activity. The acetic acid conversion rate of the single metal $\mathrm{Zn}(\mathrm{OAc})_{2}$ / AC catalyst was $19.9 \%$. When the molar ratio of $\mathrm{Zn}$ : Co: Ni was 1:0.3:0.05, the ternary metal catalyst $\mathrm{Zn} 1 \mathrm{Co} 0.3 \mathrm{~N} 0.05 / \mathrm{AC}$ showed quite excellent catalytic activity, reaching $36.4 \%$.
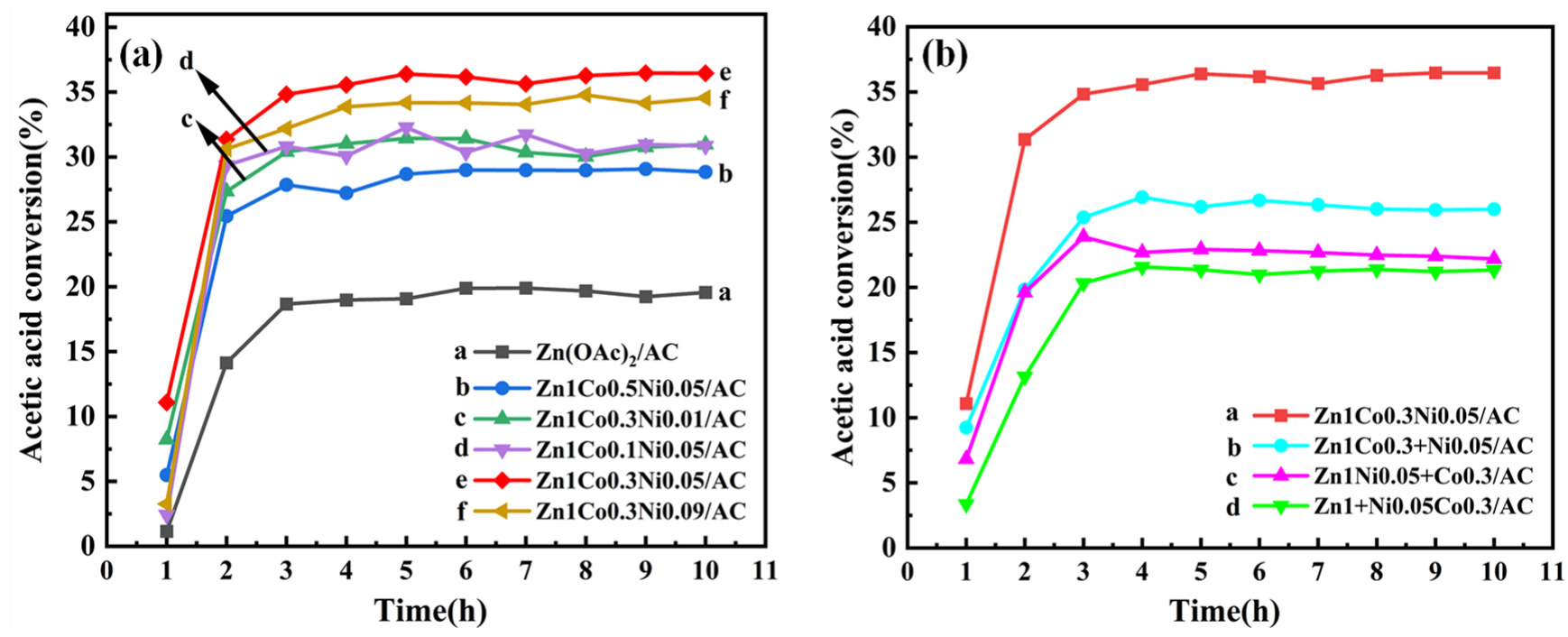

Figure 1. Conversion of acetic acid based on $\mathrm{Zn}(\mathrm{OAc})_{2} / \mathrm{AC}$ and $\mathrm{Zn}-\mathrm{Co}-\mathrm{Ni} / \mathrm{AC}$ catalysts (a), ternary catalysts $(\mathbf{b})$. Reaction conditions: temperature $(\mathrm{T})=220^{\circ} \mathrm{C}$, GHSV $\left(\mathrm{C}_{2} \mathrm{H}_{2}\right)=500 \mathrm{~h}^{-1}$, and a feed molar ratio $\mathrm{C}_{2} \mathrm{H}_{2}(\mathrm{~g}) / \mathrm{CH}_{3} \mathrm{COOH}(\mathrm{g})=3$. 
In order to study the mechanism of the ternary catalysts, $\mathrm{Zn} 1 \mathrm{Co} 0.3+\mathrm{Ni} 0.05 / \mathrm{AC}$, $\mathrm{Zn} 1 \mathrm{Ni0} .05+\mathrm{Co} 0.3 / \mathrm{AC}$, and $\mathrm{Zn} 1+\mathrm{Ni} 0.05 \mathrm{Co} 0.3 / \mathrm{AC}$ catalysts were prepared, respectively. The catalysts prepared by secondary impregnation did not show excellent performance, as shown in Figure 1b. The ternary catalysts prepared by a one-step process showed that $\mathrm{Zn}$, $\mathrm{Co}$, and Ni elements were uniformly mixed and evenly dispersed on the carrier, which is supported by the data in Figure S2. Strong interactions occurred between the additive and the active component, when the catalysts were prepared by secondary impregnation, the original active sites were covered by the co-catalysts, which reduced the performance of the active components, and the pore blockage of the carriers was also responsible for the reduced activity.

\subsection{Structure Characterizations of the As-Prepared Catalysts}

The structural parameters such as specific surface area $\left(\mathrm{S}_{\mathrm{BET}}\right)$, pore volume $(\mathrm{V})$, and pore diameter $(\mathrm{D})$ of the catalyst were measured with ASAP 2460 pore size analyzer. As can be seen from Table 2, as the added amount of Co and Ni gradually increased, the specific surface area and pore volume of the catalyst decreased. On the one hand, due to the dilution effect, the loading of the active component reduces the ratio of the carrier in the catalyst, and as the loading amount of the active component increases, the proportion of the carrier gradually decreases, and the dilution effect becomes more significant. On the other hand, the loaded cobalt acetate, nickel acetate, and zinc acetate blocked or filled some pores of the carrier, resulting in the reduction of the specific surface area and pore volume of the catalyst. With more loadings, the more pores were filled or blocked by the carrier; therefore, the less the specific surface area and total pore volume of the catalyst will be. The results also indicate the successful preparation of the $\mathrm{Zn}-\mathrm{Co}-\mathrm{Ni} / \mathrm{AC}$ ternary catalysts.

Table 2. Textural parameters of catalysts.

\begin{tabular}{cccc}
\hline Samples & $\left.\mathbf{S}_{\text {BET }} \mathbf{( m}^{\mathbf{2}} \mathbf{g}^{\mathbf{- 1}}\right)$ & $\mathbf{V}\left(\mathbf{c m}^{\mathbf{3}} \mathbf{g}^{\mathbf{- 1}}\right)$ & $\mathbf{D} \mathbf{( n m})$ \\
\hline $\mathrm{AC}$ & 1134.4 & 0.61 & 2.16 \\
Zn(OAc) 2 /AC & 929.9 & 0.50 & 2.17 \\
Zn1Co0.1Ni0.05/AC & 795.7 & 0.42 & 2.09 \\
Zn1Co0.3Ni0.05/AC & 718.9 & 0.39 & 2.12 \\
Zn1Co0.5Ni0.05/AC & 621.2 & 0.34 & 2.11 \\
Zn1Co0.3Ni0.01/AC & 730.5 & 0.33 & 2.10 \\
Zn1Co0.3Ni0.09/AC & 724.6 & 0.38 & 2.12 \\
\hline
\end{tabular}

\subsection{Effect of Co and Ni on the Zinc Catalyst}

By analyzing the causes of catalyst deactivation in the previous work, it was found that the adsorption capacity of the catalyst to the reactant molecules is closely related to its catalytic performance [23].

In Figure 2a, the central temperature of the acetylene desorption peaks of $\mathrm{Zn}(\mathrm{OAc})_{2} / \mathrm{AC}$, $\mathrm{Zn} 1 \mathrm{Co0} .3 / \mathrm{AC}$, and $\mathrm{Zn} 1 \mathrm{Ni0} 0.05 / \mathrm{AC}$ catalysts are around $473^{\circ} \mathrm{C}$, but the temperature of the acetylene desorption peak for the $\mathrm{Zn} 1 \mathrm{Co} 0.3 \mathrm{Ni0} 0.05 / \mathrm{AC}$ catalyst is around $447{ }^{\circ} \mathrm{C}$, The area of the desorption peak of $\mathrm{Zn} 1 \mathrm{Co} 0.3 \mathrm{Ni0.05/AC}$ catalyst is significantly smaller than that of the other catalysts. It can be seen from Figure $2 b$, the temperatures of acetic acid desorption peaks for the $\mathrm{Zn} 1 \mathrm{Co} 0.3 \mathrm{Ni0} 0.05 / \mathrm{AC}$ catalyst are about $198^{\circ} \mathrm{C}$ and $354{ }^{\circ} \mathrm{C}$, which for $\mathrm{Zn}(\mathrm{OAc})_{2} / \mathrm{AC}$ catalyst are around $198^{\circ} \mathrm{C}$ and $302^{\circ} \mathrm{C}$, while the peak areas of the Co and $\mathrm{Ni}$ co-doped catalysts have significantly increased. We found that the introduction of cobalt and nickel elements could also improve the adsorption of acetic acid by the catalyst. The above results indicate that there is a strong synergistic effect among $\mathrm{Zn}, \mathrm{Co}$, and $\mathrm{Ni}$, which reduces the adsorption amount and intensity of acetylene and enhances the adsorption amount and intensity of acetic acid, thus enhancing the activity of the catalysts. Besides, the increase of the desorption peak area may also due to the additives which make the nanoparticles of active components more uniformly dispersed and more 
active sites exposed on the carrier. In summary, the excellent catalytic performance of Zn1Co0.3Ni0.05/AC catalyst is attributed to the addition of $\mathrm{Co}$ and $\mathrm{Ni}$, which have changed the adsorption performance of the catalyst and the one-step synthesis could induce more active sites.
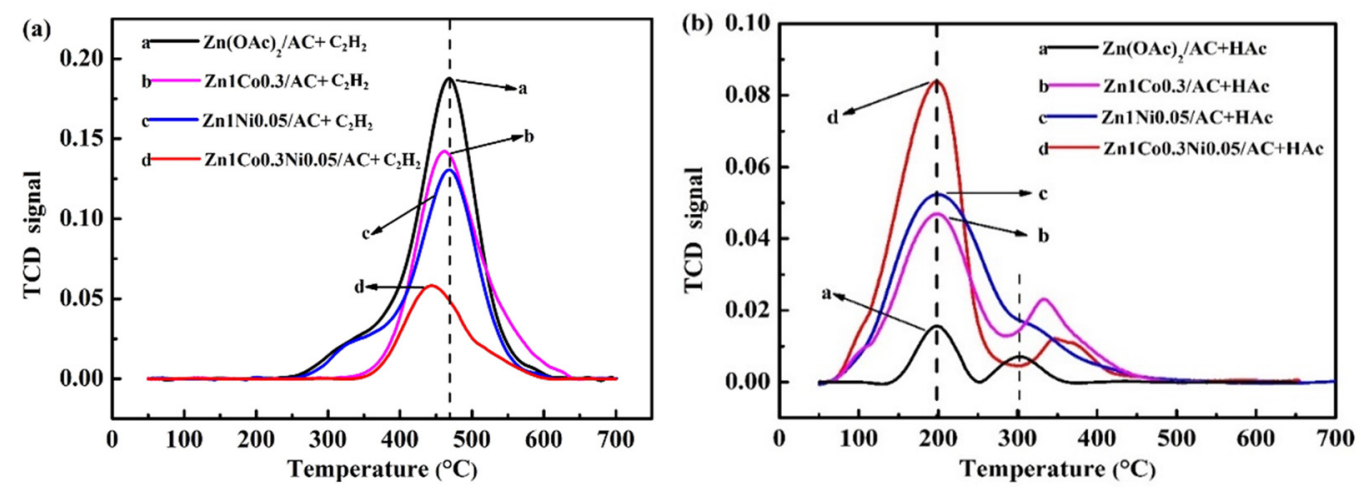

Figure 2. TPD results of the $\mathrm{Zn}(\mathrm{OAc})_{2} / \mathrm{AC}$ and $\mathrm{Zn} 1 \mathrm{Co} 0.3 \mathrm{Ni0} .05 / \mathrm{AC}$ with $\mathrm{C}_{2} \mathrm{H}_{2}$ (a) and $\mathrm{HAc}(\mathbf{b})$, respectively.

In order to explore the chemical state of $\mathrm{Zn}$ element on the surface of the catalyst, we conducted XPS experiment analysis. As shown in Figure 3a, the XPS full spectrum of the $\mathrm{Zn}(\mathrm{OAc})_{2} / \mathrm{AC}$ catalyst proves the presence of $\mathrm{C}, \mathrm{O}$, and $\mathrm{Zn}$. The XPS full spectrum of the $\mathrm{Zn} 1 \mathrm{Co} 0.3 \mathrm{Ni0.05} / \mathrm{AC}$ catalyst shows the existence of $\mathrm{C}, \mathrm{O}, \mathrm{Co}, \mathrm{Zn}$, Ni elements, which means $\mathrm{Co}$ and $\mathrm{Ni}$ were successfully doped in $\mathrm{Zn}(\mathrm{OAc})_{2} / \mathrm{AC}$ catalyst, this is consistent with the energy dispersive spectrometer (EDS) result in Table S2. In Figure 3b, the binding energy positions of $\mathrm{Zn} 2 \mathrm{p} 3 / 2$ and $\mathrm{Zn} 2 \mathrm{p} 1 / 2$ of the $\mathrm{Zn}(\mathrm{OAc})_{2} / \mathrm{AC}$ catalyst in Figure $3 \mathrm{~b}$ are located at $1022.2 \mathrm{eV}$ and $1045.3 \mathrm{eV}$, respectively, which is consistent with the binding energy positions of $\mathrm{Zn} 2 \mathrm{p}$ of zinc acetate reported in the literature $[27,28]$. The binding energy positions of $\mathrm{Zn} 2 \mathrm{p} 3 / 2$ and $\mathrm{Zn} 2 \mathrm{p} 1 / 2$ of the $\mathrm{Zn} 1 \mathrm{Co} 0.3 \mathrm{Ni} 0.05 / \mathrm{AC}$ catalyst shift toward the lower binding energy, which are located at $1021.6 \mathrm{eV}$ and $1044.8 \mathrm{eV}$, respectively. This indicates that the addition of $\mathrm{Co}$ and $\mathrm{Ni}$ changes the electron cloud density around the active site through electron transfer. The $\mathrm{Co}^{2+}$ and $\mathrm{Ni}^{2+}$ standard reduction electrode potentials are higher than that of $\mathrm{Zn}^{2+}$, leading to the electrons transfers from the former to the latter, which enhances the electron density of the $\mathrm{Zn}$ active center and thus increases the adsorption capacity of the catalyst for acetic acid. For Zn1Co0.3Ni0.05/AC catalyst, the active component is the element zinc, the elements cobalt and nickel are the promoter. The promoter plays the most critical role by changing the outer electron density of the active component zinc, resulting in a shift in the binding energy of the zinc element. As Richardson, J.T. [29] writes in his book, Principles of Catalyst Development, promoter interactions on active component can also be structural or electronic. This is consistent with the analytical results of TPD experiments.

In order to verify that the doping of $\mathrm{Co}$ and $\mathrm{Ni}$ elements would make a uniform $\mathrm{Zn}$ element distribution, the catalysts were subjected to TEM-mapping tests, as shown in Figure $4 \mathrm{~b}$. There is a significant inhomogeneity in the distribution of $\mathrm{Zn}$ elements, which present as agglomeration in $\mathrm{Zn}(\mathrm{OAc})_{2}$ / AC catalyst. However, as displayed in Figure 4c,e,f, not only Zn elements are uniformly dispersed, but also $\mathrm{Ni}$ and Co are equally uniformly dispersed. This is mainly due to the interaction between $\mathrm{Zn}, \mathrm{Co}$, and $\mathrm{Ni}$, which is also consistent with the XPS data. 

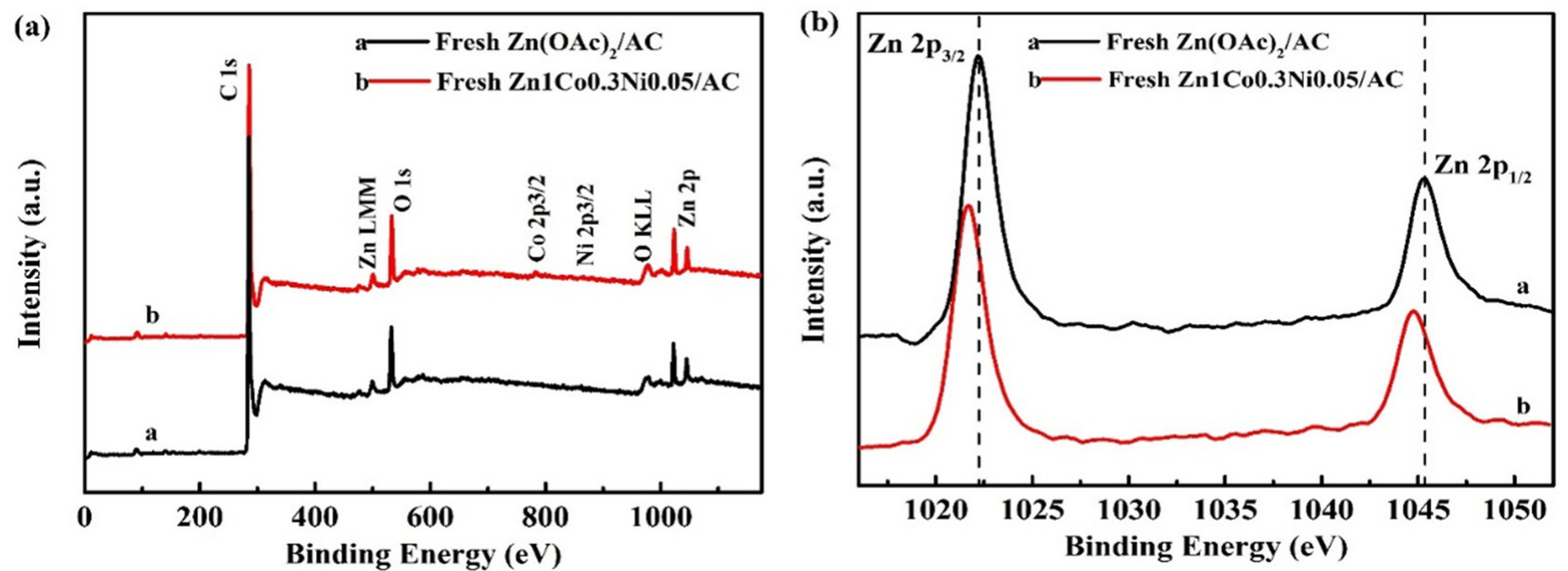

Figure 3. XPS spectra of the fresh $\mathrm{Zn}(\mathrm{OAc})_{2}$ / AC and Zn1Co0.3Ni0.05/AC catalysts: (a) XPS survey spectra of catalysts; (b) XPS analysis of $\mathrm{Zn} 2 \mathrm{p}$ region for catalysts.
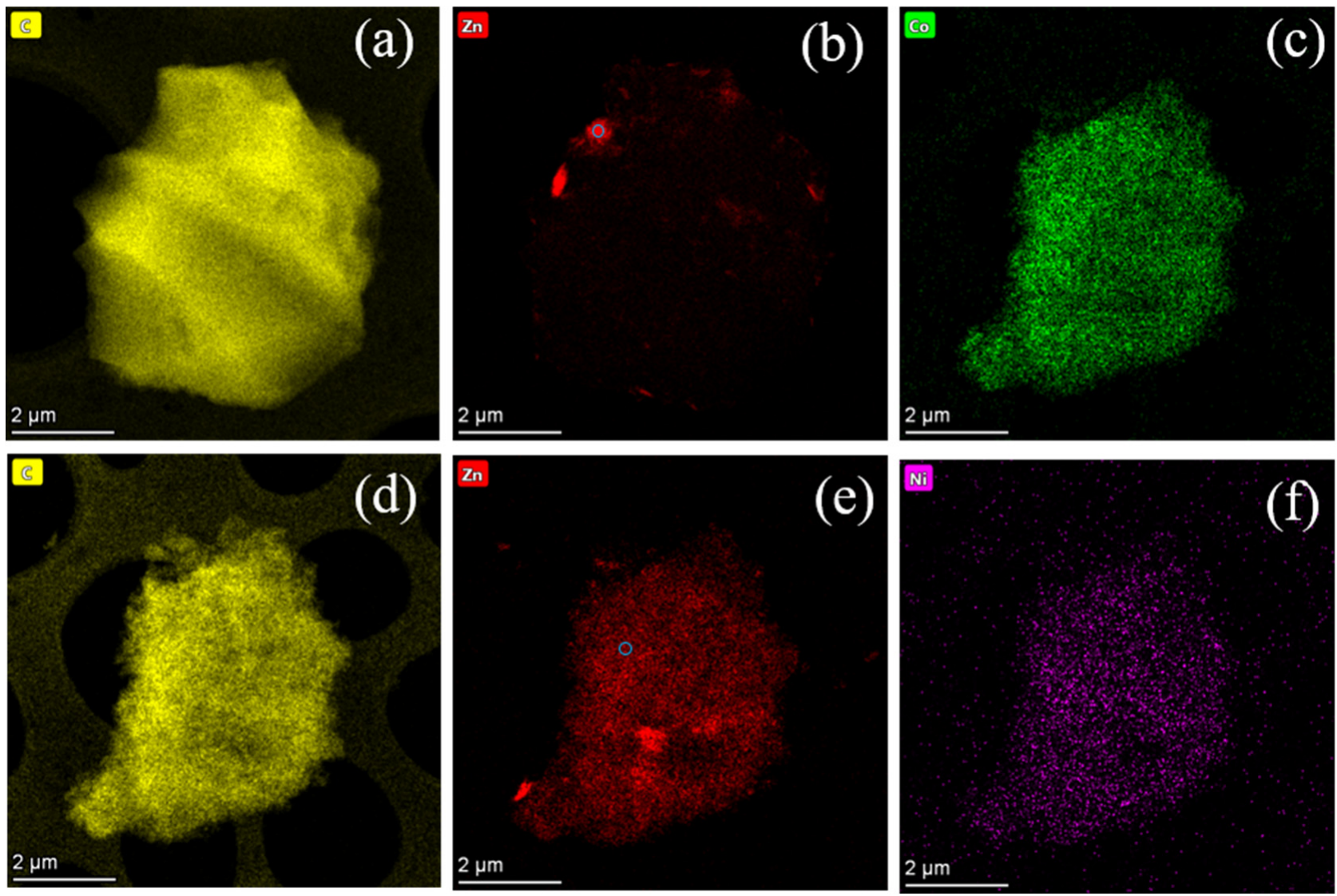

Figure 4. TEM-mapping images of catalysts: $(\mathbf{a}, \mathbf{b}) \mathrm{Zn}(\mathrm{OAc})_{2} / \mathrm{AC},(\mathbf{c}-\mathbf{f}) \mathrm{Zn} 1 \mathrm{Co} 0.3 \mathrm{Ni0} 05 / \mathrm{AC}$.

\subsection{Catalytic Stability of the $\mathrm{Zn}-\mathrm{Co}-\mathrm{Ni} / \mathrm{AC}$ Catalysts}

Lifetime testing under laboratory reaction conditions is to explore the industrial application prospects of the $\mathrm{Zn} 1 \mathrm{Co} 0.3 \mathrm{Ni0} .05$ / AC catalyst. The results are shown in Figure 5 . There is a certain reaction induction period for the $\mathrm{Zn} 1 \mathrm{Co} 0.3 \mathrm{Ni} 0.05 / \mathrm{AC}$ catalyst, during this time, the activity of the catalyst gradually increased. After about $4 \mathrm{~h}$ of reaction, the acetic acid conversion rate reaches a maximum of $36.4 \%$. After $120 \mathrm{~h}$ of testing, the conversion rate is still up to $30.1 \%$, which is $82.3 \%$ of the highest conversion rate. The maximum value of $\mathrm{Zn}(\mathrm{OAc})_{2} / \mathrm{AC}$ catalyst acetic acid conversion rate is $19.9 \%$, after $120 \mathrm{~h}$ 
of reaction, the conversion rate drops to $11.8 \%$, only $59.3 \%$ of the highest conversion rate, these results show that adding the appropriate amount of $\mathrm{Co}$ and Ni can greatly improve the stability of zinc acetate catalyst.

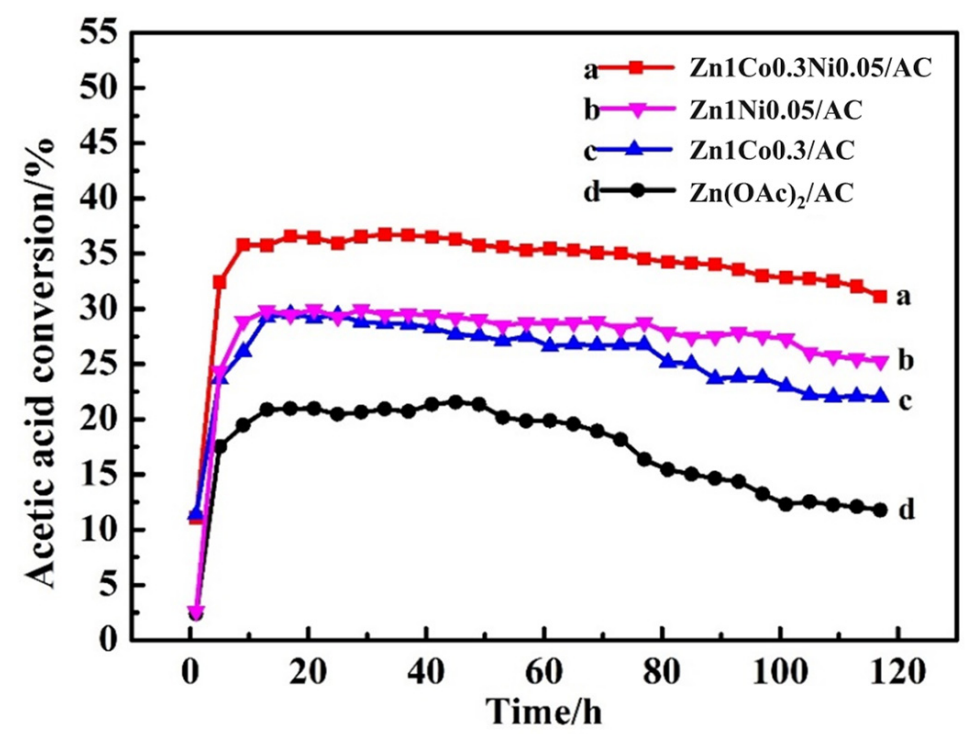

Figure 5. Lifetime test of catalysts.

Reaction conditions: Temperature $(\mathrm{T})=220^{\circ} \mathrm{C}$, GHSV $\left(\mathrm{C}_{2} \mathrm{H}_{2}\right)=500 \mathrm{~h}^{-1}$, and a feed molar ratio $\mathrm{C}_{2} \mathrm{H}_{2}(\mathrm{~g}) / \mathrm{CH}_{3} \mathrm{COOH}(\mathrm{g})=3$.

The loadings of $\mathrm{Zn}(\mathrm{OAc})_{2}, \mathrm{Co}(\mathrm{OAc})_{2}$, and $\mathrm{Co}(\mathrm{OAc})_{2}$ in the $\mathrm{Zn}(\mathrm{OAc})_{2} / \mathrm{AC}$ and $\mathrm{Zn} 1 \mathrm{Co} 0.3 \mathrm{Ni0.05/AC}$ catalysts fresh and used are listed in Table 3, respectively. The loadings of $\mathrm{Zn}(\mathrm{OAc})_{2}$ in the two catalysts before the reaction are $8.69 \%$ and $8.75 \%$, respectively, which are lower than the theoretical loading of $10 \%$, this can be attributed to the presence of bound water in $\mathrm{Zn}(\mathrm{OAc})_{2}$. The loadings of $\mathrm{Zn}(\mathrm{OAc})_{2}$ in the reacted $\mathrm{Zn}(\mathrm{OAc})_{2} / \mathrm{AC}$ and $\mathrm{Zn} 1 \mathrm{Co} 0.3 \mathrm{Ni0} .05 / \mathrm{AC}$ catalysts are $7.51 \%$ and $7.81 \%$, separately, and the loss rates of $\mathrm{Zn}(\mathrm{OAc})_{2}$ in the $\mathrm{Zn}(\mathrm{OAc})_{2} / \mathrm{AC}$ and $\mathrm{Zn} 1 \mathrm{Co} 0.3 \mathrm{Ni0} .05 / \mathrm{AC}$ catalysts are calculated to be $13.6 \%$ and $11.9 \%$, respectively. The same method was used to obtain the loss rates of $\mathrm{Co}(\mathrm{OAc})_{2}$ and $\mathrm{Ni}(\mathrm{OAc})_{2}$, which are $64.8 \%$ and $10.5 \%$, respectively. The results show that the addition of $\mathrm{Co}$ and $\mathrm{Ni}$ did not inhibit the loss of zinc acetate during the reaction. After the reaction period, the catalytic activity of the catalyst decreases to some extent.

Table 3. Loading of $\mathrm{Zn}(\mathrm{OAc})_{2}, \mathrm{Co}(\mathrm{OAc})_{2}$ and $\mathrm{Ni}(\mathrm{OAc})_{2}$ in the catalysts.

\begin{tabular}{|c|c|c|c|}
\hline Catalysts & $\mathrm{Zn}(\mathrm{OAc})_{2}$ Loading, $\mathbf{w t} \%$ & Co $(\mathrm{OAc})_{2}$ Loading, wt $\%$ & $\mathrm{Ni}(\mathrm{OAc})_{2}$ Loading, wt $\%$ \\
\hline $\mathrm{Zn}(\mathrm{OAc})_{2} / \mathrm{AC}$ & 8.69 & - & - \\
\hline Zn1Co0.3Ni0.05/AC & 8.75 & 2.61 & 0.38 \\
\hline $\mathrm{Zn}(\mathrm{OAc})_{2} / \mathrm{AC}-\mathrm{U}$ & 7.51 & - & - \\
\hline Zn1Co0.3Ni0.05/AC-U & 7.71 & 0.92 & 0.34 \\
\hline
\end{tabular}

The thermogravimetric analysis of $\mathrm{Zn} 1 \mathrm{Co} 0.3 \mathrm{Ni0} 0.05 / \mathrm{AC}$ and $\mathrm{Zn}(\mathrm{OAc})_{2} / \mathrm{AC}$ catalysts before and after the reaction is shown in Figure 6. It can be seen from Figure 6a that the fresh catalyst $\mathrm{Zn}(\mathrm{OAc})_{2} / \mathrm{AC}$ has a weight loss of $6.5 \%$ between $275^{\circ} \mathrm{C}$ and $448{ }^{\circ} \mathrm{C}$. When the temperature exceeds $448^{\circ} \mathrm{C}$, the weight loss rate of the catalyst is extremely fast, mainly due to the carrier activated carbon burning. After the reaction, the weight loss of the catalyst $\mathrm{Zn}(\mathrm{OAc})_{2} / \mathrm{AC}$ between $275-448^{\circ} \mathrm{C}$ is as high as $28.1 \%$, which related to the combustion of carbon on the surface area of the catalyst. After adding Co and Ni species, the weight loss of fresh catalyst Zn1Co0.3Ni0.05/AC between $267-411{ }^{\circ} \mathrm{C}$ was $5.0 \%$, and the weight loss of the catalyst after reaction in this temperature range was $8.94 \%$. 
We calculated the amount of carbon deposition on the catalyst surface by calculating the difference in weight loss between the catalyst before and after the reaction. After $120 \mathrm{~h}$ of reaction, the $\mathrm{Zn}(\mathrm{OAc})_{2}$ / AC surface area of the catalyst has a large carbon content of $21.6 \%$. Carbon deposits tend to block the activated carbon pores and reduce the specific surface area to cover the active sites, resulting in a reduction in catalyst conversion. The surface area carbon content of the catalyst $\mathrm{Zn} 1 \mathrm{Co} 0.3 \mathrm{Ni} 0.05 / \mathrm{AC}$ after the reaction is only 3.94\%, indicating that the addition of $\mathrm{Co}$ and $\mathrm{Ni}$ effectively suppresses the production of carbon in the surface area of the catalyst, so the stability of $\mathrm{Zn} 1 \mathrm{Co} 0.3 \mathrm{Ni} 0.05 / \mathrm{AC}$ catalyst is improved.
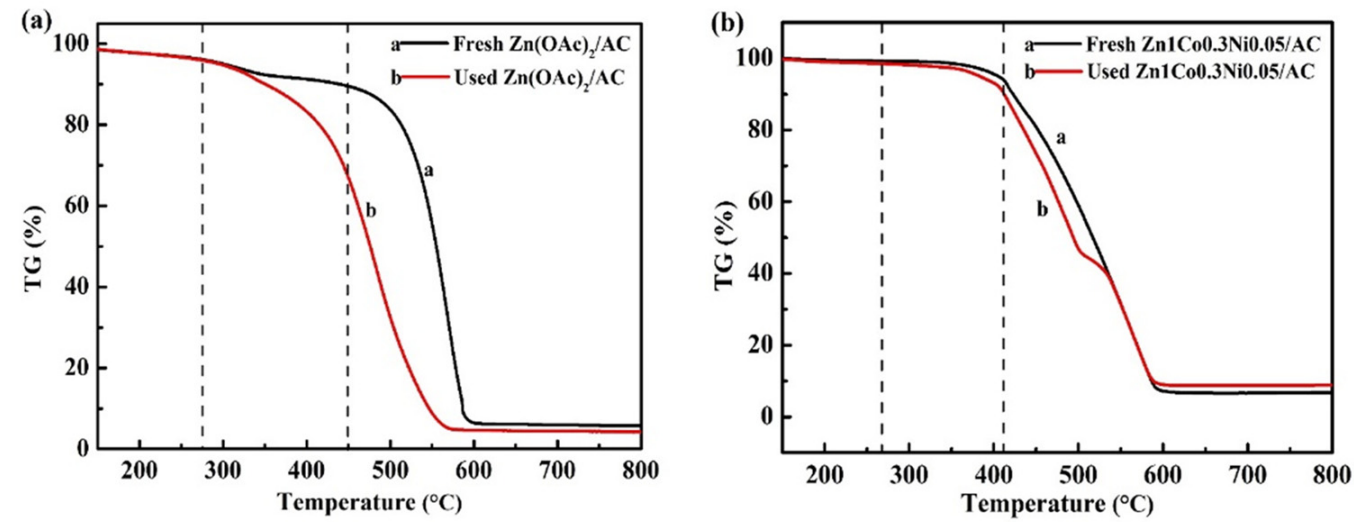

Figure 6. TG curves of the fresh and used $\mathrm{Zn}(\mathrm{OAc})_{2} / \mathrm{AC}$ catalyst (a) and $\mathrm{Zn1Co0.3Ni0.05/AC}$ catalyst (b).

\section{Materials and Methods}

\subsection{Materials}

$\mathrm{AC}\left(\mathrm{pH}=6-8\right.$, coconut carbon), $\mathrm{Zn}(\mathrm{OAc})_{2} \cdot 2 \mathrm{H}_{2} \mathrm{O}(99.8 \%$, Aldrich, Saint Louis, $\mathrm{MO}$, USA), $\mathrm{Ni}(\mathrm{OAc})_{2} \cdot 4 \mathrm{H}_{2} \mathrm{O}$ (99.8\%, Aldrich), $\mathrm{Co}(\mathrm{OAc})_{2} \cdot 4 \mathrm{H}_{2} \mathrm{O}\left(99.8 \%\right.$, Aldrich); $\mathrm{C}_{2} \mathrm{H}_{2}$ (gas,99\%), $\mathrm{CH}_{3} \mathrm{COOH}$ (acetic acid liquid,99\%).

\subsection{Catalysts Preparation}

Pretreatment of catalyst carrier: The commercial coconut shell activated carbon was passed through a sieve and screened, the 60-80-mesh activated carbon was used as a carrier. In order to remove the ash and impurities from the carrier without changing the surface structure of the activated carbon, the carrier was fully washed with deionized water. The cleaned carrier was put into the oven at $120^{\circ} \mathrm{C}$ to dry, and finally the pre-treated carrier was obtained.

Added a certain mass of $\mathrm{Zn}(\mathrm{OAc})_{2} \cdot 2 \mathrm{H}_{2} \mathrm{O}, \mathrm{Co}(\mathrm{OAc})_{2} \cdot 4 \mathrm{H}_{2} \mathrm{O}$, and $\mathrm{Ni}(\mathrm{OAc})_{2} \cdot 4 \mathrm{H}_{2} \mathrm{O}$ was added into $3 \mathrm{~mL}$ of deionized water and then fully stirred. $2.0 \mathrm{~g}$ of pretreated activated carbon carrier was put into a beaker, the prepared active component dissolved solution was added drop by drop to the carrier using the isometric impregnation method. After stirring for $24 \mathrm{~h}$ at room temperature, the target product was dried in an oven at $80{ }^{\circ} \mathrm{C}$ for $10 \mathrm{~h}$. A series of $\mathrm{Zn}-\mathrm{Co}-\mathrm{Ni} / \mathrm{AC}$ catalysts with different molar ratios were prepared by the same method and named as Zn1Co0.1Ni0.05/AC, Zn1Co0.3Ni0.05/AC, Zn1Co0.5Ni0.05/AC, $\mathrm{Zn} 1 \mathrm{Co} 0.3 \mathrm{Ni0.01/AC}$, and Zn1Co0.3Ni0.09/AC, respectively, while the monometallic catalyst $\mathrm{Zn}(\mathrm{OAc})_{2} / \mathrm{AC}$ was prepared as control. $\mathrm{Zn}(\mathrm{OAc})_{2} \cdot 2 \mathrm{H}_{2} \mathrm{O}$ and $\mathrm{Co}(\mathrm{OAc})_{2} \cdot 4 \mathrm{H}_{2} \mathrm{O}$ were prepared in a certain ratio to form a mixed solution, impregnated with $A C$ of an equal volume solution, stirred and dried to obtain $\mathrm{Zn1Co0.3/AC} \mathrm{catalyst.} \mathrm{A} \mathrm{certain} \mathrm{proportion} \mathrm{of}$ $\mathrm{Ni}(\mathrm{OAc})_{2} \cdot 4 \mathrm{H}_{2} \mathrm{O}$ solution was prepared, and then impregnated with $\mathrm{Zn} 1 \mathrm{Co} 0.3 / \mathrm{AC}$ catalyst in the same volume solution, stirred and dried to obtain Zn1Co0.3 + Ni0.05/ AC catalyst. Using the same method, Zn1Ni0.05 + Co0.3/AC and Zn1 + Co0.3Ni0.05/AC catalysts were prepared by changing the addition order of co-catalysts. The theoretical loading of zinc acetate in all catalysts was $10 \mathrm{wt} \%$. 


\section{Conclusions}

A ternary $\mathrm{Zn}-\mathrm{Co}-\mathrm{Ni}$ / AC catalyst was prepared by using $\mathrm{Zn}$ as the main catalyst and $\mathrm{Co}$ and $\mathrm{Ni}$ as co-catalysts, and then we have investigated its reaction mechanism and application prospects. It was found that a strong interaction between the co-catalyst and the main catalyst occurred, leading to the enhanced the electron density of the active center atoms mainly through electron transfer, which in turn promoted the adsorption of acetic acid molecules and reduced the adsorption of acetylene molecules by the catalyst. The catalytic performance of $\mathrm{Zn}-\mathrm{Co}-\mathrm{Ni} / \mathrm{AC}$ was better than the corresponding mono- and bimetallic catalysts, and the conversion of acetic acid was $36.4 \%$ under the same conditions, and the conversion was still as high as $30.1 \%$ after $120 \mathrm{~h}$ of reaction. The ternary catalysts showed higher activity and stability compared to the conventional $\mathrm{Zn}(\mathrm{OAc})_{2} / \mathrm{AC}$ catalysts. This work complements the studies on auxiliaries in acetylene acetylation reactions and also provides a reference for the application of ternary catalysts in other fields. However, this study still has limitations, although the loss of Zn can be suppressed by the co-catalyst, the loss of $\mathrm{Zn}$ still happens and stopping the loss of the active component is still an urgent problem to be solved.

Supplementary Materials: The following are available online at https:/ / www.mdpi.com/article/10 .3390 / catal11111271/s1, Figure S1: Flow Chart-Experimental setup, Table S1: Calculation of carbon balance, Figure S2: X-ray diffraction patterns for $\mathrm{Zn}(\mathrm{OAc})_{2} / \mathrm{AC}$ and $\mathrm{Zn} 1 \mathrm{Co} 0.3 \mathrm{Ni0.05} / \mathrm{AC}$ catalysts, Table S2: Element content of $\mathrm{Zn}(\mathrm{OAc})_{2} / \mathrm{AC}$ and $\mathrm{Zn1Co0.3Ni0.05/AC} \mathrm{catalysts,} \mathrm{Figure} \mathrm{S3:} \mathrm{TEM} \mathrm{image}$ for $\mathrm{Zn}(\mathrm{OAc})_{2} / \mathrm{AC}(\mathrm{a})$ and $\mathrm{Zn} 1 \mathrm{Co} 0.3 \mathrm{Ni0.05/AC(b)}$ catalysts, Figure S4: TOF and TON of catalysts, Detailed description of the particle size distribution (PSD) measurement process. (Figures S5-S12), Figure S13: TEM images of catalysts: (a) Zn(OAc) / AC, (b) Zn1Co0.3Ni0.05/AC, Figure S14: Gas chromatogram spectrum of the products, Figure S15: Gas chromatogram spectrum of the products (acetaldehyde), Figure S16: Gas chromatogram spectrum of the products (vinyl acetate), Figure S17: Gas chromatogram spectrum of the products (acetic acid).

Author Contributions: X.W. and B.D. designed and conceived of the experiments. Z.X. and P.H. performed the experiments. Z.X. and Y.C. analyzed the data. B.D. contributed reagents/materials/analysis tools. Z.X. wrote the paper with direction from X.W., M.Z. and B.D. All authors have read and agreed to the published version of the manuscript.

Funding: This work was financially supported by the State Key Research and Development Project of China (2016YFB03016032), and the Major Science and Technology Project of Xinjiang Bingtuan (nos. 2017AA007, 2020AA004).

Data Availability Statement: Data is contained within the article or supplementary material.

Acknowledgments: Thanks to the China Foundation and the Xinjiang Bingtuan.

Conflicts of Interest: The authors declare no conflict of interest.

\section{References}

1. Gonzalez Caranton, A.R.; da Silva Pinto, J.C.C.; Stavale, F.; Barreto, J.; Schmal, M. Statistical analysis of the catalytic synthesis of Vinyl acetate over Pd-Cu/ $\mathrm{ZrO}_{2}$ nanostructured based catalysts. Catal. Today 2020, 344, 108-117. [CrossRef]

2. Han, Y.F.; Kumar, D.; Goodman, D.W. Particle size effects in vinyl acetate synthesis over Pd/SiO 2. J. Catal. 2005, 230, 353-358. [CrossRef]

3. Li, Z.J.; Thuening, T.; Tysoe, W.T. The adsorption of ethylene on Au/Pd (100) alloy surfaces. Surf. Sci. 2016, 646, 65-71. [CrossRef]

4. Schobert, H. Production of acetylene and acetylene-based chemicals from coal. Chem. Rev. 2014, 114, 1743-1760. [CrossRef]

5. Bartley, W.J.; Jobson, S.; Harkreader, G.G.; Kitson, M.; Lemanski, M.F. Catalysts and Processes for the Manufacture of Vinyl Acetate. U.S. Patent 5,185,308, 2 September 1993.

6. Motahari, K.; Rempel, G.; Lashkarara, S.; Ghaseminezhad, K.; Borumandnejad, A.; Hatami, B. Modelling of deactivation of Pd-Au catalyst in vinyl acetate synthesis from oxidation of ethylene and acetic acid in the gaseous phase. Can. J. Chem. Eng. 2016, 94, 506-511. [CrossRef]

7. Huang, Y.; Dong, X.; Yu, Y.; Zhang, M. A comprehensive comparative DFT study on adsorption and reactions involved in vinyl acetate synthesis from acetoxylation of ethylene on pure Pd (100) and Pd-Au (100): Elucidating the role of Au. Appl. Surf. Sci. 2016, 387, 1021-1028. [CrossRef] 
8. Xu, H.; Yu, T.; Li, M. Zinc Acetate Immobilized on Mesoporous Materials by Acetate Ionic Liquids as Catalysts for Vinyl Acetate Synthesis. J. Chem. 2015, 2015, 238287. [CrossRef]

9. Miyazawa, S. The Prevention of the Activity Decrease of Metallic Oxide Catalyst in Synthetic Process of Vinyl Acetate. J. Soc. Chem. Ind. Jpn. 1963, 66, 39-44.

10. Miyazawa, S. The Change of the Activity and Composition of Metallic Oxide Catalyst in Synthetic Process of Vinyl Acetate. J. Soc. Chem. Ind. Jpn. 1961, 64, 1460-1463.

11. Bong, H.K.; Binh, H.H.; Kurlyandskaya, I.I.; Nyrkova, A.N.; Yamandii, D.I.; Temkin, O.N. Regularities of adsorption of zinc acetate from aqueous solutions onto the surface of modified activated carbons. Russ. J. Appl. Chem. 2014, 86, 1691-1701. [CrossRef]

12. Abanto-Chavez, H.J.; Kozhemyakina, I.A.; Bong, H.K.; Temkin, O.N. Adsorption of Zn (OAc) 2 from Aqueous Solutions on the Surface of Activated Carbons Modified with Acetic Acid. Russ. J. Appl. Chem. 2003, 76, 1418-1422.

13. Yan, F.-W.; Guo, C.-Y.; Yan, F.; Li, F.-B.; Qian, Q.-L.; Yuan, G.-Q. Vinyl acetate formation in the reaction of acetylene with acetic acid catalyzed by zinc acetate supported on porous carbon spheres. Russ. J. Phys. Chem. A 2010, 84, 796-801. [CrossRef]

14. Temkin, O.N.; Abanto-Chavez, H.I.; Hoang, K.B. Kinetic models of vinyl acetate synthesis on new-generation zinc acetate catalysts. React. Kinet. Catal. Lett. 2000, 41, 638-654. [CrossRef]

15. Dong, X.; Wang, Y.; Yu, Y.; Zhang, M. Density Functional Theory Investigation on the Synthesis Mechanism of Vinyl Acetate from Acetylene and Acetic Acid Catalyzed by Ordered Mesoporous Carbon-Supported Zinc Acetate. Ind. Eng. Chem. Res. 2018, 57, 7363-7373. [CrossRef]

16. El-Sawi, M.; Emig, G.; Hofmann, H. A study of the kinetics of vinyl acetate synthesis. Chem. Eng. J. 1977, 13, 201-211. [CrossRef]

17. Zhang, M.H.; Zhuang, J.Y.; Wu, X.Y.; Yu, Y.Z. Experimental and theoretical insights into the cyclotrimerization of acetylene during vinyl acetate synthesis. Chem. Eng. J. 2019, 378, 122183. [CrossRef]

18. Zhang, M.; Wu, X.; Huang, X.; Yang, B.; Yu, Y. DFT investigations on the conversion of acetylene to undesired vinyl acetylene during vinyl acetate synthesis. Comput. Theor. Chem. 2017, 1115, 253-260. [CrossRef]

19. Morrow, B.A. The initial mechanism of vinyl acetate synthesis from acetic acid and acetylene catalyzed by active carbon-zinc acetate. J. Catal. 1984, 86, 328-332. [CrossRef]

20. Hu, L.B.; Xu, Z.; He, P.J.; Wang, X.G.; Tian, Z.Q.; Yuan, H.F.; Yu, F.; Dai, B. Zinc and Nitrogen-Doped Carbon In-Situ Wrapped ZnO Nanoparticles as a High-Activity Catalyst for Acetylene Acetoxylation. Catal. Lett. 2020, 150, 1155-1162. [CrossRef]

21. He, P.; Huang, L.; Wu, X.; Xu, Z.; Zhu, M.; Wang, X.; Dai, B. A Novel High-Activity Zn-Co Catalyst for Acetylene Acetoxylation. Catalysts 2018, 8, 239. [CrossRef]

22. He, P.; Wu, X.; Huang, L.; Zhu, M.; Wang, X.; Dai, B. Acetoxylation of acetylene to vinyl acetate monomer over bimetallic Zn-Ni/AC catalysts. Catal. Commun. 2018, 112, 5-9. [CrossRef]

23. Wu, X.Y.; He, P.J.; Wang, X.G.; Dai, B. Zinc acetate supported on N-doped activated carbon as catalysts for acetylene acetoxylation. Chem. Eng. J. 2017, 309, 172-177. [CrossRef]

24. Zhu, F.; Zhu, M.; Kang, L. B-doped activated carbon as a support for a high-performance Zn-based catalyst in acetylene acetoxylation. Green Energy Environ. 2020. [CrossRef]

25. Sakla, R.; Kaushik, R.; Kumar, V.; Jose, D.A.; Ghosh, A.; Mariappan, C.R. Light-induced water oxidation by polymorphs of the Zn-Co-Ni oxide spinel catalyst: A comparative study. Sustain. Energ Fuels 2019, 3, 786-792. [CrossRef]

26. Zhu, L.L.; Hao, C.; Wang, X.H.; Guo, Y.N. Fluffy Cotton-Like GO/Zn-Co-Ni Layered Double Hydroxides Form from a Sacrificed Template GO/ZIF-8 for High Performance Asymmetric Supercapacitors. Acs Sustain. Chem. Eng. 2020, 8, 11618-11629. [CrossRef]

27. Zhao, X.Q.; Wang, Y.J.; Wang, S.F.; Yang, H.J.; Zhang, J.Y. Synthesis of MDI from dimethyl carbonate over solid catalysts. Ind. Eng. Chem. Res. 2002, 41, 5139-5144. [CrossRef]

28. Li, F.; Li, W.B.; Li, J.; Xue, W.; Wang, Y.J.; Zhao, X.Q. Investigation of supported Zn (OAc)(2) catalyst and its stability in N-phenyl carbamate synthesis. Appl. Catal. A Gen. 2014, 475, 355-362. [CrossRef]

29. Richardson, J.T. Principles of Catalyst Development; Springer Science \& Business Media: New York, NY, USA, 1989 ; pp. 35-37. 